\title{
El ser literario de la psicología
}

\author{
José Morales González \\ Universidad Michoacana de San Nicolás de Hidalgo \\ josemoralesgonzalez@gmail.com
}

Resumen

El presente trabajo argumenta que es posible trazar The present work argues that it is possible to trace a una mirada literaria hacia el interior de la literary perspective in psychology, which pays psicología, que ponga el acento en el trabajo de attention to the work of writing of the principal escritura que llevaron a cabo autores centrales de la authors of the discipline. This perspective will disciplina. Esta mirada definiría a la psicología como define the psychology as a reading club; its un círculo de lectura, cuya delimitación estaría dada delimitation does not correspond to a reality field no por un campo de estudio de la realidad definido de defined beforehand, but for a conjoint of common antemano, sino por un conjunto de lecturas lectures. The literary tradition concurs with the compartidas. La tradición literaria concurre con works that are considered as cardinals for the aquellas obras que, de forma más o menos psychology. In other words, the classics in psychology consensuada, se consideran cardinales para la are so, not because of the actual application of its psicología; es decir, los clásicos de la psicología concepts or theoretical ideas, but because of its adquieren este calificativo por su cualidad literaria, más literary nature.

que por la vigencia de sus conceptos o de sus aportaciones teóricas.

Esta mirada literaria implica reconocer la condición act of reading it retakes its absolute force and de práctica humana, perecedera y efímera, pero que en presence.

la lectura retoma su plena y absoluta fuerza y

presencia.

Palabras clave: Historia de la psicología; Keywords: Group processes; History of psychology; Tradición literaria; Ensayo; Lectura

El ser literario de la psicología es hecho de lectura y cobra cuerpo en la escritura. Las obras que suelen llamarse clásicas de la psicología ponen de manifiesto que el valor en el trabajo de escritura alcanza niveles fundamentales.

Estas obras resultan ser la base de la disciplina no tanto por sus aportaciones teóricas o conceptuales, sino por su calidad de escritura que invita a la relectura al no agotarse a la primera mano; su constante referencia es un volver a su lectura, no sólo una recuperación conceptual, pues en los clásicos no opera el criterio del desarrollo teórico ni del progreso científico; hay en ellos más de metáfora que de concepto, más de estilo que de estadística.

La práctica elemental de la psicología es extender este ser literario, ya que la introducción al estudio de esta materia es a través de la lectura y sobre todo de la lectura de clásicos, o en su defecto de lecturas referentes a ellos, y culmina en la puesta en el escenario de la escritura de la investigación.

Pero lo que aquí se llama ser literario de la psicología ha sido sistemáticamente negado, pues aceptar que la psicología está hecha de escritura es equipararla a cualquier práctica escrita como la literatura o el periodismo. El texto científico usa una retórica para que la escritura pase desapercibida, como si 
los datos fueran mostrados sin intermediarios, como si al leer los resultados de tal investigación estuviésemos accediendo a la realidad misma. Si fuera así, no costaría tanto aprender el formato artículo de publicación, estandarizado por las revistas científicas.

Hay escritores, como John Dewey o Maurice Halbwachs, que usan la escritura como herramienta de pensamiento. Sus disertaciones son al vuelo de la escritura. Sus textos son su laboratorio de trabajo. Hay grandes escritores dentro de la tradición reconocida como propia de la psicología. No hace falta ir fuera de los textos propios de psicología, si es que los hay, para encontrar el ser literario.

Nos asomaremos a una tradición dentro de la psicología, la psicología de las masas, en la que el ser literario es protagónico.

Las obras de la psicología de las masas, aquella de principios de siglo encabezada por Gustave Le Bon y Gabriel Tarde, porta dos componentes que aquí son de interés. Hay en ellas un trabajo de escritura confesado por sus autores y hay además un objeto de estudio de naturaleza estética. Es decir, los autores de psicología de las masas dicen emplear, y empelan, un estilo de escritura que sea capaz de describir aquello que los ocupa, la masa, la multitud, pues más que interesarse por su explicación, la descripción del fenómenos es la marca de estas obras.

En La era de las multitudes, Serge Moscovici incluye, además de los psicólogos ya bien reconocidos, novelistas, cuentistas y poetas, como parte de una tradición dedicada a la escritura de la masa. Maupassant, Zola, Baudelaire, son algunos de ellos. Pero Moscovici no reclama el reconocimiento de la procedencia y la originalidad de las ideas de estos literatos que ahora se piensan como ideas propias de la psicología social, pues dice, son más bien propias de la época; lo que sí parece afectarle más a Moscovici es la forma en que estos escritores describieron a la masa. Por ejemplo, de Maupassant, de quien incluye extensas citas, apunta: "es imposible decir mejor lo que el novelista ha expresado de manera tan perfecta", dicho esto a pesar de que Moscovici difiera en más de algún punto con el escritor francés. Sin embargo lo rescata, por su estilo, por su manera de describir su encuentro con las masas.

Así va Moscovici introduciendo a esta psicología, con un texto plagado de referencias a la literatura francesa, utilizando expresiones como baño de multitud, o diciendo fogosamente que la masa es una inefable orgía, una santa prostitución del alma, citando el poema "La Turba", de Baudelaire.

A Moscovici lo contagia este ánimo literario para referirse a las masas y procede a momentos de esta forma en su tratado: "Estos átomos diversos, estos granos de multitud se reúnen en mezclas inestables y violentas. Forman una especie de gas que tiende a explotar en el vacío de la sociedad despojada de sus autoridades y valores, un gas cuya potencia explosiva aumenta con el volumen y lo domina todo."

Pareciera que quien escribe sobre la masa se ve en la necesidad de emplear metáforas para describir su objeto de estudio estético, por fascinante, atractivo y en cierta medida todavía misterioso. Así Gabriel Tarde en su libro La opinión y la multitud (1901) confiesa que las figuraciones hidráulicas son inminentes:

Hagamos notar que estas comparaciones hidráulicas vienen, naturalmente, a la pluma cada vez que se trata de multitudes, así como de públicos; precisamente, se asemejan en esto. Una multitud en marcha una tarde de fiesta pública circula con una lentitud y con numerosos remolinos que nos traen a la memoria la idea de un 
río sin cauce preciso. Porque nada es menos comparable a una multitud, sino es un público. Más bien son cursos de agua, cuyo régimen está mal definido.

Gustave Le Bon, de igual manera, en su libro de 1895, recurre a las metáforas acuíferas al hablar sobre las ideas que impregnan a la masa escribiendo: "Las ideas fundamentales pueden compararse a la masa formada por las aguas de un río que cursa lentamente; las ideas pasajeras, a las pequeñas ondas, siempre cambiantes, que agitan a su superficie y que aun cuando carezcan realmente de importancia, resultan más visibles que el propio fluir del río."

$Y$ es que, como dice Tarde para comenzar y justificar su libro, "la multitud no solamente atrae y arrastra irremediablemente a su espectador, sino que su nombre ejerce un atractivo prestigioso sobre el lector contemporáneo y algunos escritores se sienten incitados a designar por esta palabra ambigua toda clase de agrupaciones humanas."

Y sin embargo y por esto mismo, a fin de siglo veinte hay quien le graba fecha de caducidad en sus mismos inicios a esta psicología de masas por "la insoluble confusión conceptual y terminológica en que se va sumiendo a cada párrafo que avanza, cuyo epítome es la múltiple ambigüedad con que denomina a su objeto de análisis" (irreconocible Pablo Fernández Christlieb, en La psicología colectiva un fin de siglo más tarde).

Ya se ve, las obras de psicología de las masas prefieren las descripciones, el cómo del contacto, del encuentro con la masa, y sus conceptos rudimentariamente definidos invitaron a ser continuamente referidos a lo largo del siglo veinte, y además como dice Moscovici: "desde hace cerca de un siglo, se ha solido limitarse a repetirlos y parafrasearlos, en un lenguaje menos crudo, más pulido, y por lo tanto relativamente más hipócrita." Esta es la prueba de su condición de clásicos.

En su libro que fue éxito de ventas desde su primera edición, Le Bon escribió: (las masas) "se asemejan a las hojas que el huracán eleva, dispersa en todas las direcciones para luego dejar caer". Elias Canetti dice que Sigmund Freud suplió su falta de experiencia de las masas con las descripciones que leyó en Le Bon. Canetti tuvo un gran malestar leyendo Psicología de las masas y análisis del yo, de Freud, "me resultó desagradable desde la primera palabra", escribió en alguna ocasión. En cambio de Le Bon dice que fue "él único que había intentado una descripción detallada" de la masa, y afirma que este autor francés estuvo influenciado, y "fascinado", por los relatos de Taine sobre la revolución francesa.

No fue sino hasta 1960 que Canetti publica Masa y poder; una obra tardía en la materia, tanto más si se le reconoce como deudora de esta tradición, a la que aporta poco si se hace caso a los manuales de psicología social e introducciones a esta psicología de masas, pues si bien recomiendan su lectura, no se le rescata teóricamente. Y es que en su escritura Canetti multiplica las metáforas para describir la masa, pero sobre todo las extiende a tal grado que en Francia calificaron despectivamente a su libro como "poema sociológico".

Reseñando la psicología social de principios de siglo de Paolo Orano, Amalio Blanco escribe en 1988:

Es la única manera de tomarse en serio esto de la Psicología social, intentar distanciarla de la descripción lírica, de la superstición y de la metafísica y para ello nada mejor que alojarla dentro de las ciencias positivas. Porque no se nos debe ocultar, comenta cargado de razón el psicólogo italiano (Orano), la existencia de una Psicología social sumida en el romance de una filosofía literaria, profundamente 
hermanada con la retórica, con la literatura, una Psicología social que puede ser una obra de arte, pero que nunca será una ciencia.

A pesar de esta preocupación, los escritos sobre las masas no lograron escapar a esta necesidad de forzar el lenguaje hasta lo poético, pues la naturaleza espontánea de la masa, hace que buscar las causas a este fenómenos resulte un tanto fatuo. Así, cuando Gabriel Tarde esbozaba causas a la formación de la masa, va desde las ideas difundidas en periódicos y recibidas por un público lector, hasta el mismo clima, pues como explicaba Tarde, "la multitud ... es más sumisa a las fuerzas de la naturaleza; depende más directamente de la lluvia o del buen tiempo, del calor o del frío; es más frecuente en verano que en invierno. Un calor de sol las reúne, un chaparrón las dispersa."

Reconocer el ser literario de la psicología y estimarlo como fundamental, ata a esta disciplina a su condición de práctica humana, sostenida no por poseer un conocimiento, sino por ensayar en la escritura una descripción de la realidad a la que se aboca, y de vez en vez lograr su objetivo: que quien lee sea partícipe de la realidad por la fuerza y presencia de estas obras durante su lectura.

\section{Formato de citación}

Morales, José. (2005). El ser literario de la psicología. Athenea Digital, 9 Disponible en http://antalya.uab.es/athenea/num9/Morales.pdf.

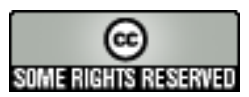

Este texto está protegido por una licencia Creative Commons.

Usted es libre de copiar, distribuir y comunicar públicamente la obra bajo las siguientes condiciones:

Reconocimiento: Debe reconocer y citar al autor original.

No comercial. No puede utilizar esta obra para fines comerciales.

Sin obras derivadas. No se puede alterar, transformar, o generar una obra derivada a partir de esta obra.

\section{Resumen de licencia}

\section{Texto completo de la licencia}

